\title{
Identifying the Factors Affecting Sustainability Cost Toward Optimization of the Project Selection Process
}

\author{
Dina Alfreahat and Zoltán Sebestyén
}

Budapest University of Technology and Economics, Budapest, Hungary, alfreahat@mvt.bme.hu

\begin{abstract}
The dialogue that competes with politics and societal issues is becoming about sustainability. Sustainability has been drawing more attention now after many years of focusing solely on technology and development and neglecting the green aspect significantly, due to the growing resource constraints and the balanced requirement of environmental, economic, and social objectives. It is becoming increasingly important for all companies across all industries. The adoption of sustainability drives stakeholders to sustain their business success in the long-term. Therefore, they have to consider more factors than profit or loss when building their strategies and change their policies in the decision-making process to prevent environmental damages. Accordingly, decisions should be dictated according to the principle of sustainability, and the impact of these decisions should be planned for years and decades. According to the researchers and experts, the adoption of sustainability is facing two major obstacles, which are the increased cost of capital or perceived cost associated with sustainability and the lack of stakeholder's demand on sustainable projects due to the wrong perception that sustainability causes cost increase. Therefore, they can take sustainability costs as a primary concern in project selection. In this regard, the purpose of this study is to explore essential factors that have an impact on sustainability cost, which in turn, affects the project selection process, based on the theoretical backgrounds from the literature. To take the sustainability costs would help us to build a cost model, including the sustainability cost of the projects and their returns, which helps stakeholders to select the optimal sustainable project from several candidate projects in the project selection decision-making process. Thus, it can lead to an increase in the potential for creating win-win situations contributing to both stakeholders and sustainability value.
\end{abstract}

(c) 2020 The Authors. Published by Budapest University of Technology and Economics \& Diamond Congress Ltd Peer-review under responsibility of the Scientific Committee of the Creative Construction Conference 2020.

Keywords: project selection, decision making, sustainability cost, sustainable project

\section{Introduction}

There is a growing interest in the world on sustainability in light of protecting the environment, reducing energy consumption, optimizing the use of natural resources, and relying more on renewable energy sources. Therefore, sectors are coming under intense pressure to respond quickly to environmental, economic, and social issues that have increased significantly in the last few years, and to involve sustainability in their goals, policies, plans and project decision-making process [1]. The concept of sustainability is not limited to the relationship of environmental development but goes beyond that to the relationship of development with economic and social dimensions. Sustainability is known as the capacity to conserve and sustain. It means identifying, developing, and fostering sustainable mindsets, practices, and policies to preserve a healthy, economically sound, and socially viable environment [2]. It is known as the triple bottom line (TBL) approach. It promotes management concentrating not just on generating value for stakeholders but also on generating environmental and social value [3]. 


\section{Sustainability in the construction sector}

The construction sector is considered as one of the largest sectors that has an important role in the movement of the national economy of any country. It has a significant impact on the environment, economy, and society. Statistics show that the construction industry is losing $57 \%$ of its resource inputs (compared to $26 \%$ in other industries) during the construction process, consumes $40 \%$ of energy, and releases approximately $40 \%$ of $\mathrm{CO}_{2}$ in the USA and other developed countries [4][5]. Therefore, sustainability is gaining greater prominence in the construction sector, and ignoring it could potentially lead to reputational or litigation risk [6]. The United Nations Global Compact (UNGC) and Accenture conducted a survey on sustainability comprising 1000 CEO's from 103 countries and 27 industries. According to the survey, $93 \%$ of CEOs considered sustainability as a key component to the future success of their business. Besides, $76 \%$ of CEOs said they believed that integrating sustainability approach into their core operations would lead to new opportunities and revenue growth [7]. Construction sector development is associated with the initiatives to encourage the development and growth of the EU economy as a whole. Europe 2020 vision for the 21st century puts forward three mutually reinforcing priorities:

- Smart growth: developing an economy based on knowledge and innovation.

- Sustainable growth: promoting a more resource-efficient, greener, and more competitive economy.

- Inclusive growth: fostering a high-employment economy delivering social and territorial cohesion. [8]

The headline goals under these priorities for 2030, which directly impact the construction sector, are as follows: minimize greenhouse gas emissions by $40 \%$ (from 1990 levels), increase the share for renewable energy by $32 \%$, and achieve improvement in energy efficiency by $32.5 \%$ [9]. People anticipate a sustainable project to be more costly. However, the sustainability concept challenges this misperception and clarifies that it could be profitable in the long term, especially when cost and environmental strategies, and program management are integrated right from the beginning into the development process [10][11]. Therefore, many sustainable projects show lower operational costs compared to conventional projects, and they prove that the high construction costs are recovered within a reasonable payback period through reduced energy and water use, and lower long-term operations and maintenance costs [11]. According to USGBC sustainable projects use $26 \%$ less energy, $13 \%$ lower maintenance costs, $27 \%$ higher occupant satisfaction, and $33 \%$ less greenhouse gas emissions [12]. In addition to direct cost savings, sustainable construction industry offers indirect economic benefits for both building owners and society [10]. Recent researches studied the relationship between economic and sustainability performance, and they prove that sustainability brings a lot of benefits to business success. Therefore, high sustainability performance contractors can expect higher international revenue growth, and sustainability performance is likely to become a competitive advantage in the international construction market [13].

Two benefits could result from the adoption of sustainability in the construction sector, which are process benefits and product benefits. Process benefits include materials savings due to reuse, recycling, conversion of waste into valuable forms, savings from safer working conditions, reduction of the costs of the activities associated with discharges, waste handling, transportation, increasing energy, and water consumption efficiency during the production process. Product benefits include higher construction quality, lower life cycle costs, and safer construction process [14]. Additionally, it improves the quality of indoor living, strengthens the culture of sustainability and its application in society, and reduce environmental pollution inside and outside the building.

The internationally recognized environmental assessment systems for buildings (e.g., LEED (Leadership in Energy and Environmental Design, USA), and BREEAM (Building Research Establishment Environmental Assessment Method, UK) are mainly focused on environmental criteria with little consideration for economic and social criteria, such as energy-saving, efficient water use, reduced $\mathrm{CO}_{2}$ emissions, improved quality of indoor living, and resource management [15]. Therefore, there is a tremendous demand in the construction industry to develop a tool that allows assessing the sustainability of the project which is considering all dimensions of sustainability. Fernandez-Sanchez and Rodrýguez-Lopez recommend criteria list to measure sustainability for infrastructure projects in Spain. They classified and prioritized sustainability indicators based on risk management standards, which resulted in a list of 30 essential criteria 
that include health and safety, economic cost/economic benefit, public participation and control on the project, Life cycle cost, project governance, and strategic management [16]. Dobrovolskiene and Tamosiuiene developed a tool to measure the sustainability of a business project in the construction industry. The authors studied 56 criteria and identified the essential 15 criteria according to the prioritization via questionnaire survey comprising six environmental, five social, and four economic. That helps the decision-makers to compare projects and make rational decisions regarding resource allocation in a project portfolio [1]. W. Der Yu proposed a construction project sustainability assessing system that comprises 4 levels with 31 sustainability indicators in order to manage and control the sustainability process for a construction project [5].

On the other hand, there is a lack of researches on sustainability cost of construction and value, which means that stakeholders cannot make the right decisions concerning sustainability. That, in turn, drives to Choose the wrong projects, which lead to wasted resources and loss of profits that could have been achieved by concentrating on other projects. Furthermore, the question of the effect of sustainability costs on net income needs to be solved [10] [17].

\section{Sustainability cost}

To build a solid foundation for any sustainable and environmentally friendly project, we must think outside the framework of the axiom factors that affect the building life cycle. The concerned parties can achieve higher returns on their investment in sustainable projects by determining the size of the gains that will be achieved through improving the performance of the project users due to the quality of the internal environment and by employing sustainability cost. Managing and controlling these elements helps in achieving financial goals in addition to environmental goals. Sustainable projects added additional costs from $1-10 \%$, due to the efficient mechanical systems that required for sustainable projects which are quite expensive and complex extended designing process [18]. Ross et al. developed a financial model emphasis that LEED-certified projects added $10 \%$ more to the costs because of the high materials and labor cost, which accounts for the largest percentage of sustainable project costs [19]. On the other hand, research indicates that saving from the sustainable project can be cover the incremental cost of the project.

Researchers have recognized the uncertainty of construction cost predictions and the need to improve the potential of cost prediction models [20]. Alshamrani developed a model to estimate the initial cost of conventional and sustainable buildings with a maximum of three floors in North America. The input variables were building area, types of structure and envelope, number of floors, and floor height [21].

Kudratova et al. developed a corporate sustainability driver model by integrating sustainability cost measurements into the traditional selection of projects. The authors found that sustainability cost estimation in traditional project selection methods produces positive returns on investment and produce positive trade-off results for both the environment and sustainability [17]. They also proposed a sustainability optimization model that considered sustainability cost and reinvestment strategy. The net present value is used to estimate the return of the project. They found that stakeholders project selection decisions and the maximum objective value obtained at an optimal 3\% sustainability cost range [22]. Recently, investors in the construction sector are becoming more attracted to the sustainability concept due to the potential of higher cost-saving benefits and higher returns [23]. Unfortunately, these benefits can only be achieved over a long period of time [24].

Attracting investors for sustainability adoption can be achieved by ensuring that sustainable projects can be executed without additional cost. Construction project costs can be divided into three categories: land, hard, and soft cost [16][17]. Land costs include land acquisition expenditures that include land purchase, transfer of title, clearing of sites, etc. Land costs are affected by factors such as location, land price and taxes, legal fees but not by the decision to be sustainable [27].

Hard costs defined as actual costs of the construction. It is a direct cost that is often influenced by the client, engineer, architects' decision. It is related to the project's physical aspect, such as architectural, civil, structural, mechanical, and electrical works [28]. It could be in the form of materials, tools, equipment and 
plants, workforce, etc. In contrast, Soft costs defined as costs generated by non-physical aspects of the construction project such as planning, management, marketing, and documentation [29]. In other words, soft costs are any other costs than building costs and are not related to construction work or materials or labor. The factors that would affect the cost of the sustainable project should be studied to understand why the cost difference occurs, thus would promote to minimize the cost increase and making the sustainable project more interesting. These factors are:

\subsection{Professionals and experts}

Professionals and experts' competence and engagement would have a significant impact on the quality and cost of a sustainable project. That is why professionals are seen as crucial players to deal with the increasing issues for vitality to live, which takes up around 3-5\% of the life cycle cost. Professionals are likely to be charged extra fees due to additional duties and responsibilities, have green experience and skills, understand environmental risk, and advise the client on sustainable projects [27].

\subsection{Technical}

From the technical and technological perspective, a sustainable project is fundamentally different from the conventional [30]. Technical factors refer to the methodological aspect of sustainable project implementation. The additional rules and regulations in sustainable projects, procurement issues, process conflicts, the availability of sustainable materials, and the skills to manage them can create a problem in sustainable projects [31][32]. The challenges associated with a complex technical requirement show the need for creating awareness, demonstration of techniques, and educational materials about sustainability to develop skills and gain experience, learn more about the process, etc. The difficulties of permits and approvals of the process for sustainable projects can also cause delays, as many building standards are not tailored to current environmentally friendly systems. These delays lead to higher risks and increased costs which in turn leads developers to think twice to build green [33].

\subsection{Technologies}

Technologies refer to the product used during the implementation process, and it divided into soft and hard technologies [34]. Soft technologies improve the construction process by using suitable structures, models, and resources to support decision-making, controlling, and evaluation activities. In contrast, hard technologies include equipment, materials, and construction processes [35]. Material price fluctuations are one of the risk factors which lead to cost overruns problems [37]. The soft costs, such as design, certification, modeling, and consulting, are taking a large part of the increased costs of sustainable projects [36]. Therefore, it is essential to concentrate on how to make these technologies widely and easily available at an acceptable cost level, which is affordable by stakeholders.

\subsection{Special requirements}

A sustainable project is likely to include additional design experts, as the green dimension of the project needs to be implemented [37]. Sustainable projects must be rigorously assessed using a sustainability performance tool and using sustainable project evaluation criteria to be certified, and a certain certification fee will be applied. This fee will be charged differently depending on the project type, project size, and assessment tool. Due to incremental demands on architects and engineers, and the additional green consultant, the sustainable project requires additional effort and time to the design and implementation phase of the project. Means estimates that the cost of designing the sustainable project will cost $5 \%$ more than the typical design cost of the conventional project [38].

\section{Conclusion}

Sustainable development transcends the narrow economic view that is sought to achieve rapid profit and increase it, to discuss means of preserving natural resources in a way that guarantees its investment for the most extended possible period, and improve the quality of the interior environment to enhance the performance of building users. Therefore, sustainability is becoming a source of competitive advantage in the international construction market, which increasingly focusing on the benefits that would be achieved after a period of time, which in turn, can lead to higher revenue growth, new market opportunities. This 
paper sheds light on sustainability in the construction sector, and since there is a massive demand in the construction industry to develop a tool that allows calculating the sustainability cost of the project, therefore, essential factors that have an impact on sustainability cost have been identified. Focusing on the sustainability aspects would help us to build a cost model, including the sustainability cost of the projects and their returns, which helps stakeholders to select the optimal sustainable project from several candidate projects in the project selection decision-making process.

\section{References}

[1] N. Dobrovolskienè, R. Tamošiūnienè, An index to measure sustainability of a business project in the construction industry: Lithuanian case, Sustainability (Switzerland), vol 8, no. 1 (2016) pp. 1-14. https://doi.org/10.3390/su8010014.

[2] Y.B. Moon, Simulation modelling for sustainability: a review of the literature, International Journal of Sustainable Engineering, vol 10, no. 1 (2017) pp. 2-19. https://doi.org/10.1080/19397038.2016.1220990.

[3] K. Kohl, Becoming a sustainable organization: a Project and portfolio management approach. 2016.

[4] U. Berardi, Building energy consumption in US, EU, and BRIC countries, Procedia Engineering, vol 118 (2015) pp. 128-136. https://doi.org/10.1016/j.proeng.2015.08.411.

[5] W. Der Yu, S.T. Cheng, W.C. Ho, Y.H. Chang, Measuring the sustainability of construction projects throughout their lifecycle: A Taiwan Lesson, Sustainability (Switzerland), vol 10, no. 5 (2018) https://doi.org/10.3390/su10051523.

[6] R.Y.J. Siew, Integrating sustainability into construction project portfolio management, KSCE Journal of Civil Engineering, vol 20, no. 1 (2016) pp. 101-108. https://doi.org/10.1007/s12205-015-0520-z.

[7] R. Hayward et al., The UN global compact-accenture CEO study on sustainability 2013, UN Global Compact Reports, vol 5, no. 3 (2014) pp. 1-60. https://doi.org/10.5848/ungc.5720.2014.0015.

[8] European Commission, A European strategy for smart, sustainable and inclusive growth, 2020.

[9] European Commission, 2030 climate \& energy framework, [Online]. Available: https://ec.europa.eu/clima/policies/strategies/2030_en\#tab-0-0. [Accessed: 09-May-2020].

[10] D. Salem, A. Bakr, Z. El Sayad, Post-construction stages cost management: Sustainable design approach, Alexandria Engineering Journal, vol 57, no. 4 (2018) pp. 3429-3435. https://doi.org/10.1016/j.aej.2018.07.014.

[11] U.S. Green Building Council (USGBC), World green building council showcases cost-effective green building benefits throughout the world, [Online]. Available: https://www.usgbc.org/articles/world-green-building-council-showcases-cost-effective-green-buildingbenefits-throughout-wo. [Accessed: 09-May-2020].

[12] U.S. Green Building Council (USGBC), Roadmap to green government buildings, 2011.

[13] Y. Tan, J.J. Ochoa, C. Langston, L. Shen, An empirical study on the relationship between sustainability performance and business competitiveness of international construction contractors, Journal of Cleaner Production, vol 93 (2015) pp. 273-278. https://doi.org/10.1016/j.jclepro.2015.01.034.

[14] R. Welford, R. Starkey, Business and the environment : a reader. Taylor \& Francis, 1996.

[15] R. Yung, J. Siew, A review of sustainability reporting tools ( SRTs ) for communities, Journal of Environmental Management, vol 5 , no. 2 (2014) pp. 39-52. https://doi.org/10.1016/j.jenvman.2015.09.010.

[16] G. Fernández-Sánchez, F. Rodríguez-López, A methodology to identify sustainability indicators in construction project management Application to infrastructure projects in Spain, Ecological Indicators, vol 10, no. 6 (Nov. 2010) pp. 1193-1201. https://doi.org/10.1016/j.ecolind.2010.04.009.

[17] S. Kudratova, X. Huang, K. Kudratov, S. Qudratov, Corporate sustainability and stakeholder value trade-offs in project selection through optimization modeling: Application of investment banking, Corporate Social Responsibility and Environmental Management, vol 27, no. 2 (2020) pp. 815-824. https://doi.org/10.1002/csr.1846.

[18] C. Lockwood, The dollars and sense of green retrofits, Washington, DC, USA, 2008.

[19] B. Ross, M. López-Alcalá, A.A. Small, Modeling the private financial returns from green building investments, Journal of Green Building, vol 2, no. 1 (2007) pp. 97-105. https://doi.org/10.3992/jgb.2.1.97.

[20] K. Bala, S.A. Bustani, B.S. Waziri, A computer-based cost prediction model for institutional building projects in Nigeria an artificial neural network approach, Journal of Engineering, Design and Technology, vol 12, no. 4 (2014) pp. 518-529. https://doi.org/10.1108/JEDT-06-2012-0026.

[21] O.S. Alshamrani, Construction cost prediction model for conventional and sustainable college buildings in North America, Journal of Taibah University for Science, vol 11, no. 2 (2017) pp. 315-323. https://doi.org/10.1016/j.jtusci.2016.01.004.

[22] S. Kudratova, X. Huang, X. Zhou, Sustainable project selection: Optimal project selection considering sustainability under reinvestment strategy, Journal of Cleaner Production, vol 203 (2018) pp. 469-481. https://doi.org/10.1016/j.jclepro.2018.08.259.

[23] M. Isa, M.M.G.M.A. Rahman, I. Sipan, T.K. Hwa, Factors affecting green office building investment in Malaysia, Procedia - Social and Behavioral Sciences, vol 105 (2013) pp. 138-148. https://doi.org/10.1016/j.sbspro.2013.11.015.

[24] C. Choi, Removing market barriers to green development: Principles and action projects to promote widespread adoption of green development practices, The Journal of Sustainable Real Estate, vol 1, no. 1 (2009) pp. 107-138.

[25] National Council of Architectural Registration Boards NCARB, Emerging Professional's Companion, 2013.

[26] S. Kubba, Handbook of Green Building Design, and Construction, Butterworth-Heinemann, p. 832. https://doi.org/10.1016/C2009-064483-4, 2012

[27] N.Z. Abidin, N.Z.M. Azizi, Identification of factors influencing costs in green projects, vol 18, no. 9 (2016) pp. 781-786.

[28] N.Z.M. A, N.Z. Abidin, A.R. Nuruddin, Soft cost elements that affect developers' decision to build green, vol 7, no. 10 (2013) pp. 432436.

[29] M. Klinger, The construction project: phases, people, terms, paperwork, processes. ABA Book Publishing, 2006.

[30] L.B. Robichaud, V.S. Anantatmula, Greening project management practices for sustainable construction, Journal of Management in Engineering, vol 27, no. 1 (2011) pp. 48-57. https://doi.org/10.1061/(ASCE)ME.1943-5479.0000030.

[31] KeTTHA, National renewable energy policy and action plan, 2008.

[32] T. Häkkinen, K. Belloni, Barriers and drivers for sustainable building, Building Research and Information, vol 39, no. 3 (2011) pp. 239-255. https://doi.org/10.1080/09613218.2011.561948.

[33] Northeast-midwest institute and Delta Institute, Removing market barriers to green development, 2008. 
[34] C. Du Plessis, A strategic framework for sustainable construction in developing countries, Construction Management and Economics, vol 25, no. 1 (2007) pp. 67-76. https://doi.org/10.1080/01446190600601313.

[35] A.R. Lapinski, M.J. Horman, D.R. Riley, Lean processes for sustainable project delivery, Journal of Construction Engineering and Management, vol 132, no. 10 (2006) pp. 1083-1091. https://doi.org/10.1061/(ASCE)0733-9364(2006)132:10(1083).

[36] LEED is broken, let's fix it, [Online]. Available: https://www.scribd.com/document/7671505/leed-is-broken. [Accessed: 11-May-2020].

[37] N.Z.M. Azizi, N.Z. Abidin, A. Raofuddin, Identification of soft cost elements in green projects: exploring experts' experience, Procedia - Social and Behavioral Sciences, vol 170 (2015) pp. 18-26. https://doi.org/10.1016/j.sbspro.2015.01.009.

[38] R. Means, Green building : project planning \& cost estimating., 3rd ed. John Wiley \& Sons, Inc., 2011. 